\title{
The use of GAD-7 as a screening tool for Generalized Anxiety Disorder in patients with epilepsy
} \author{
Guilherme de Faria Pinheiro ${ }^{1}$ \\ ${ }^{1}$ Neurology Department, Hospital Municipal Doutor José de Carvalho Florence, São José dos Campos-SP, Brazil \\ ${ }^{2}$ Neurophysiology Department, Hospital São Paulo (Universidade Federal de São Paulo), São Paulo - SP, Brazil \\ ${ }^{3}$ Psychiatry Department, Hospital São Paulo (Universidade Federal de São Paulo), São Paulo - SP, Brazil
}

Rafael Batista João ${ }^{1 *}$, Richard Mady Nunes ${ }^{2}$, Murilo Brasileiro Ramos Galvão ${ }^{3}$, Raquel Mattos Filgueiras ${ }^{1}$ and

Submission: January 22, 2018; Published: February 02, 2018

*Corresponding author: Rafael Batista João, Neurology Department, Hospital Municipal Doutor José de Carvalho Florence, São José dos Campos SP, Brazil, Email: Rafjoao@hotmail.com

\begin{abstract}
Epilepsy is a prevalent neurological disease affecting approximately 2 - 3\% of world's population. As is known, patients with epilepsy (PWE) are more predisposed to present comorbid psychiatric disorders, however, many of them remain underdiagnosed. In last years, several screening tools with the objective of assessing anxiety symptoms in different sub-populations have been proposed, including in PWE. Relevant publications concerning this issue were identified by searching several widely used databases. Our results disclosed that the Generalized Anxiety Disorder - 7 Scale (GAD-7) was considered a valid and reliable screening tool for detecting Generalized Anxiety Disorder in patients with epilepsy. After literature review, we concluded that the use of GAD-7 in these patients is becoming an emergent clinical practice. Further studies are needed to investigate the applicability of this screening tool in larger samples of PWE in primary care.

Keywords : Epilepsy; Anxiety; Psychiatric Co-morbidities; Generalized Anxiety Disorder; Screening Tools; Generalized Anxiety Disorder - 7 Scale; GAD-7

Abbreviations : HAM: Hamilton Anxiety Rating Scale; HADS-A: Hospital Anxiety and Depression Scale; GAD-2: Generalized Anxiety Disorder-2 scale; GAD-7: Generalized Anxiety Disorders-7 scale; GAD: Generalized Anxiety Disorder; DSM-IV: 4th Edition of the Diagnostic and Statistical Manual of Mental Disorders; PWE: Patients with Epilepsy; N: Number; RP: Research Participants; PPV: Positive Predictive Value; NPV: Negative Predictive Value
\end{abstract}

\section{Introduction}

Epilepsy is a prevalent neurological disease affecting approximately $2-3 \%$ of world's population [1]. Individuals who suffer from this condition are more predisposed to present comorbid psychiatric disorders (approximated prevalence of $6 \%$ ). When considering mental disorders related to epilepsy, prevalence occurs as follows: Depression (24-74\%), Anxiety Disorders (10-25\%), Psychosis (2-7\%) and Personality Disorders (1-2\%) [2]. This association complicates treatment and clinical management of those patients $[3,4]$. Despite the high prevalence of psychiatric disorders in epilepsy, many of them remain underdiagnosed and untreated [5]. The crescent number of studies concerning this topic is an important mark for the multidisciplinarity of epileptology.

\section{Method}

Relevant publications were identified after searching several widely used databases, including PubMed Central ${ }^{\circledR}$ (last searched January 17, 2018), SciELO (last searched January 17, 2018), Google Scholar (last searched January 17, 2018), Europe PubMed Central ${ }^{\circ}$ (last searched January 19, 2018) and Wiley Online Library (last searched January 19, 2018). The databases were searched by using the following terms: Epilepsy, Anxiety, Psychiatric Comorbidities, Generalized Anxiety Disorder, Screening tools, Generalized Anxiety Disorder-7 scale and GAD7.

\section{Results}

Our review disclosed that, in last years, several screening tools with the objective of assessing anxiety symptoms in different sub-populations have been proposed. Some examples are: HAM (Hamilton Anxiety Rating Scale) [6], HADS-A (Hospital Anxiety and Depression Scale) [7], GAD-2 (Generalized Anxiety Disorder - 2 Scale) [8] and GAD-7 (Generalized Anxiety Disorder - 7 Scale) [9]. The GAD-7 is an evaluation instrument elaborated by Spitzer et al. [9] and validated by Kroenke and Spitzer et al. [10], in United States of America. Based on the $4^{\text {th }}$ Edition of the Diagnostic and Statistical Manual of Mental Disorders (DSM-IV) Generalized Anxiety Disorder (GAD) criteria, seven items aiming a self-report measure of anxiety symptoms were developed to compound a brief questionnaire [11]. It takes a few minutes to complete GAD-7. Each item is scored from 0 to 3 (total score of 21 points). As proposed in the original validation article, a total 
score > 9 predicts a greater chance of diagnosing GAD in general population [10].

Recently, some studies have considered the use of GAD-7 as a screening tool for anxiety symptoms in patients with epilepsy (PWE). According to our review, the first relevant paper about that issue, published in 2014, was MEPSY (Multicenter Trial of Epilepsy and Psychiatric), a multicentric cross-sectional study involving 243 eligible PWE in South Korea. In that study, after multidisciplinary evaluation and statistical analysis of data, Seo et al. concluded that GAD-7 is a valid and reliable screening tool for detecting GAD in PWE. The author suggested a cut-off score of $>6$ in this population, with a sensitivity of $92,2 \%$, a specificity of $89,1 \%$, a positive predictive Value (PPV) of $69,1 \%$ and a negative predictive value (NPV) of 97,7\%. In MEPSY, PWE with GAD were more likely to be women ( $p$-value $=0,011$ ), to have had the onset of epilepsy in an earlier age (p-value $=0,006)$ and were less likely to take psychiatric medication ( $\mathrm{p}$-value $<0,001)$ when compared with patients without GAD [12].

In 2015, Tong et al. validated the GAD-7 among chinese PWE in a consecutive cohort of 213 eligible research participants. In that paper, authors also suggested a cut-off score of $>6$ (sensitivity of $94 \%$ and specificity of $91,4 \%$; PPV of $77 \%$ and NPV of 98\%) [13]. According to results of that study, there were more patients with complex partial seizures - now called focal onset impaired awareness seizures [14] - diagnosed with GAD ( $\mathrm{p}$-value $=0,046$ ), while for other seizure types no such difference was noted. Seizures were more frequent $(\mathrm{p}$-value $=$ 0,001 ) and more recent ( $p$-value $=0,013$ ) in PWE with GAD when compared to PWE without GAD. PWE of the GAD group were more likely to be taking multiple antiepileptic drugs ( $\mathrm{p}$-value = 0,042 ). Patients with idiophatic epilepsy had less GAD ( $p$-value $=0,013)[13]$.

The most recent article concerning use of GAD-7 as a screening tool for GAD in PWE $(\mathrm{N}=145)$ included in this review was published by Micolaud-Franchi et al, in 2016. According to the authors, the cut-off point that showed maximized sensitivity and specificity was 7 (sensitivity of $95,9 \%$ and specificity of $76 \%$; PPV of $67,1 \%$ and NPV of $97,3 \%$ ). In that study, there was no statistically significant difference in demographic and clinical characteristics between PWE with and without GAD [15]. The compilated data of studies cited in this review were exposed on Table 1.

Table 1: Compilated data of studies concerning validation of the GAD-7 among PWE.

\begin{tabular}{|c|c|c|c|c|c|c|c|c|}
\hline \multirow{4}{*}{$\begin{array}{c}\text { Studies } \\
\text { (GAD-7 - } \\
\text { PWE) }\end{array}$} & Authors & $\begin{array}{c}\text { Publication } \\
\text { Year }\end{array}$ & $\begin{array}{c}\mathrm{N} \text { of eligible } \\
\text { RP }\end{array}$ & $\begin{array}{l}\text { Cut-off score } \\
\text { suggested }\end{array}$ & $\begin{array}{l}\text { Sensitivity of } \\
\text { Cut-off score }\end{array}$ & $\begin{array}{l}\text { Specificity of } \\
\text { Cut-off score }\end{array}$ & $\begin{array}{l}\text { PPV of Cut- } \\
\text { off score }\end{array}$ & $\begin{array}{l}\text { NPV of Cut-off } \\
\text { score }\end{array}$ \\
\hline & Seo et al & 2014 & 243 & $>6$ & $92,2 \%$ & $89,1 \%$ & $69,1 \%$ & $97,7 \%$ \\
\hline & Tong et al & 2015 & 213 & $>6$ & $94 \%$ & $91,4 \%$ & $77 \%$ & $98 \%$ \\
\hline & $\begin{array}{l}\text { Micolaud- } \\
\text { Franchi et al }\end{array}$ & 2016 & 145 & $>7$ & $95,9 \%$ & $76 \%$ & $67,1 \%$ & $97,3 \%$ \\
\hline
\end{tabular}

Studies (GAD-7-PWE): Studies concerning validation of the GAD-7 among PWE; GAD-7: Generalized Anxiety Disorder-7 scale; PWE: Patients With Epilepsy; N: Number; RP: Research Participants; PPV: Positive Predictive Value; NPV: Negative Predictive Value.

The discrepancy of cut-off scores of GAD-7 in studies including PWE compared to studies in general population $(>$ 6 versus $>9$, respectively) could reflect a tendency for PWE to underestimate their worry symptoms due to chronic anxiety related to their epileptic disorder per se [16]. Another factor considered by Seo et al., Tong et al. and Micolaud-Franchi et al. was the perceived stigma of people with epilepsy, which might lead them to an unwillingness to disclose their feelings when answering the questionnaire $[12,13,15]$. In addition, it is worthy to cite the cross-cultural differences between samples studied, as suggested by Seo et al. [12].

\section{Conclusion}

After our review, we concluded that the use of GAD-7 as a screening tool for detecting GAD in PWE is becoming an emergent clinical practice. Further studies are needed to investigate the applicability of GAD-7 in larger samples of PWE in primary care. Strategies to assess anxiety and depression symptoms in people with epilepsy are very important, since identification and treatment of psychiatric disorders are related to better clinical outcomes and control of seizures.

\section{Conflicts of Interest}

None.

\section{References}

1. Barragan E (2012) Epilepsy and related psychiatric conditions. In Rey JM (Edn.), IACAPAP e-Textbook of Child and Adolescent Mental Health. Geneva: International Association for Child and Adolescent Psychiatry and Allied Professions.

2. Gaitatzis A, Trimble MR, Sander JW (2004) The psychiatric comorbidity of epilepsy. Acta Neurol Scand 110(4): 207-220.

3. Davies S, Heyman I, Goodman R (2003) A population survey of mental health problems in children with epilepsy. Deve Med Child Neurol 45(5): 292-295.

4. Devisnky O (2003) Psychiatric comorbidity in patients with epilepsy: implications for diagnosis and treatment. Epilepsy Behav 4(4): S2-S10.

5. Krishnamoorthy ES, Trimble MR, Blumer D (2007) The classification of neuropsychiatric disorders in epilepsy: a proposal by the ILAE commission on psychobiology of epilepsy. Epilepsy Behav 10(3): 349353.

6. Hamilton M (1959) The assessment of anxiety states by rating. Br J Med Psychol 32(1): 50-55. 
7. Zigmond AS, Snaith RP (1983) The hospital anxiety and depression scale. Acta Psychiatr Scand 67(6): 361-370.

8. Skapinakis P (2007) The 2-item Generalized Anxiety Disorder scale had high sensitivity and specificity for detecting GAD in primary care. Evid Based Med 12(5): 149.

9. Spitzer RL, Kroenke K, Williams JBW, Löwe B (2006) A brief measure for assessing generalized anxiety disorder: the GAD-7. Arch Intern Med 166(10): 1092-1097.

10. Kroenke K, Spitzer RL, Williams JBW, Monahan PO, Löwe B (2007) Anxiety disorders in primary care: prevalence, impairment, comorbidity, and detection. Ann Intern Med 146(5): 317-325.

11. American Psychiatric Association (2000) Diagnostic and Statistical Manual of Mental Disorders. (4 ${ }^{\text {th }}$ Edn.); Text Rev, Washington, USA.

12. Seo JG, Cho YW, Lee SJ, Lmee JJ, Kim JE, et al. (2014) Validation of the generalized anxiety disorder-7 in people with epilepsy: a MEPSY study. Epilepsy Behav 35: 59-63.

This work is licensed under Creative Commons Attribution 4.0 License

DOI: 10.19080/PBSIJ.2018.08.555737
13. Tong X, An D, McGonigal A, Park S, Zhou D (2016) Validation of the Generalized Anxiety Disorder-7 (GAD-7) among Chinese people with epilepsy. Epilepsy Res 120: 31-36.

14. Fisher RS (2017) An overview of the 2017 ILAE operational classification of seizure types. Epilepsy Behav 70: 271-273.

15. Micoulaud FJ, Lagarde S, Barkate G, Dufournet B, Besancon C (2016) Rapid detection of generalized anxiety disorder and major depression in epilepsy: Validation of the GAD-7 as a complementary tool to the NDDI-E in a French sample. Epilepsy Behav 57: 211-216.

16. Beyenburg S, Mitchell AJ, Schmidt D, Elger CE, Reuber M (2005) Anxiety in patients with epilepsy: systematic review and suggestions for clinical management. Epilepsy Behav 7(2): 161-171.

\section{Your next submission with Juniper Publishers will reach you the below assets}

- Quality Editorial service

- Swift Peer Review

- Reprints availability

- E-prints Service

- Manuscript Podcast for convenient understanding

- Global attainment for your research

- Manuscript accessibility in different formats ( Pdf, E-pub, Full Text, Audio)

- Unceasing customer service

Track the below URL for one-step submission https://juniperpublishers.com/online-submission.php 